\title{
ПОЛУЧЕНИЕ СОРБЦИОННЫХ МАТЕРИАЛОВ НА ОСНОВЕ ТОРФА
}

\author{
() А.Р. Цыганов ${ }^{1}$, А.Э. Томсон ${ }^{1}$, К.Г. Боголицын ${ }^{2}$, Т.В. Соколова ${ }^{1}$, В.П. Стригуцкий ${ }^{I}$ В.С. Пехтерева ${ }^{l}$, \\ С.Б. Селянина ${ }^{2 *}$, Л.Н. Парфенова ${ }^{2}$, М.В. Труфанова ${ }^{2}$ \\ ${ }^{1}$ Институт природопользования НАН Беларуси, ул. Скорины, 10, Минск, \\ 220114 (Республика Беларусь) \\ ${ }^{2}$ Институт экологических проблем Севера УрО РАН, ул. Набережная \\ Северной Двины, 17, Архангельск, 163002 (Россия), e-mail: smssb@yandex.ru
}

Разработаны научные основы получения сорбционных материалов на основе торфа для решения проблем очистки воздушных сред. Показано, что механизмами усиления сорбционной активности и улучшения технологических характеристик сорбентов на основе торфа при модификации его низкими концентрациями слабых кислот является трансформация систем полисопряжения и связанная с нею перестройка структуры органоминеральных комплексов. Взаимодействие модифицирующих кислот с органической матрицей торфа происходит по механизму «макрокоординации». Производственными испытаниями обоснованы целесообразность использования торфяных сорбентов для обеззараживания предприятий сельскохозяйственного профиля от аммиака.

Ключевые слова: полимерная матрица торфа, сорбция, системы полисопряжения, сорбция аммиака, механизм «макрокоординации».

Работа выполнена при поддержке ФФИ РБ (проект Х 12P-147), РФФИ (проект 12-03-90018-

Бел_а) и программы межрегиональных и межведомственных фундаментальных исследований УрО PAH (проект 12-C-5-1017)

\section{Введение}

\footnotetext{
Цыганов Александр Риммович - доктор биологических наук, академик НАНБ, главный научный сотрудник, e-mail: nature@ecology.basnet.by

Томсон Алексей Эммануилович - кандидат химических наук, заместитель директора,

e-mail: altom@ecology.basnet

Боголищын Константин Григорьевич - директор, главный научый сотрудник, доктор химических наук, e-mail: bogolitsyn@iepn.ru

Соколова Тамара Владимировна - старший научный сотрудник, кандидат химических наук, e-mail: nature@ecology.basnet.by

Стригуиякий Виктор Петрович - старший научный сотрудник, кандидат химических наук,

e-mail: nature@ecology.basnet.by

Пехтерева Виктория Владимировна - научный

сотрудник, e-mail: nature@ecology.basnet.by

Селянина Светлана Борисовна - кандидат технических наук, доцент, старший научный сотрудник,

e-mail: smssb@yandex.ru

Парфенова Лариса Николаевна - кандидат химических наук, заведующая лабораторией,

e-mail: solombalka@yandex.ru

Труфанова Марина Витальевна - кандидат химических наук, научный сотрудник, e-mail: mtrufanova@ya.ru
}

На современных предприятиях сельскохозяйственного профиля, предусматривающих содержание животных и птиц в закрытых помещениях в течение длительного времени при высокой концентрации поголовья на единицу площади, важное значение имеет очистка воздуха от вредных продуктов метаболизма. В частности, аммиак, образующийся при разложении различных органических азотсодержащих веществ, создает благоприятную среду для активизации условно патогенной микрофлоры на слизистой оболочке дыхательных путей, в результате чего ослабляется резистентность организма и возникают различные заболевания, особенно легочные [1].

Одним из достаточно эффективных и недорогих способов дезодорации воздуха является использование фильтрующих устройств, заполненных дешевыми поглощающими материалами природного происхождения - корой деревьев, картоном, землей, торфом. В отношении последнего в [2] выявлена способность сорбировать газообразный аммиак в количестве,

\footnotetext{
* Автор, с которым следует вести переписку.
} 
в несколько раз превышающем его ионообменную емкость, что делает торф перспективным сорбентом для очистки воздуха сельскохозяйственных предприятий. Известна также модификация органогенных сорбентов аммиака минеральными кислотами с целью увеличения их поглощающей способности [2, 3].

Ранее нами показано [4], что сверхэквивалентная сорбция аммиака торфом обусловлена энергетически выгодным образованием его молекулами мостиковых водородных и донорно-акцепторных связей с полисопряженными фрагментами. В представляемом исследовании рассмотрены возможность и механизм усиления сорбционной активности аммиака торфа в результате обработки не разрушающими структуру его органического вещества слабыми кислотами (фосфорная, лимонная и щавелевая).

\section{Экспериментальная часть}

В качестве объекта исследования выбраны образцы торфа верхового (пушицевый со степенью разложения $\mathrm{R}=40 \%$, зольностью $\mathrm{A}^{\mathrm{c}}=2,2 \%$ и ионообменной емкостью $\mathrm{OE}=1,2$ мг-экв $\Gamma^{-1}$ ) и низинного (осоковый $\mathrm{c} \mathrm{R}=20 \%, \mathrm{~A}^{\mathrm{c}}=5,8 \%, \mathrm{OE}=0,6 \mathrm{Mг-экв} \cdot \Gamma^{-1}$ ) типов. Получение модифицированных сорбентов производилось экструзионным способом путем продавливания формуемой массы через фильеры диаметром 3 мм с последующей сушкой и сепарированием. Процесс подготовки формуемой массы торфа с модифицирующими кислотами сводился к орошению торфа растворами кислот концентрации $10^{-4}$ и $10^{-2}$ моль ${ }^{-1}$ при модуле (М), т.е. соотношении жидкой фазы к твердой, $2.5: 1$ и $5: 1$. Определение технологических характеристик осуществлялось по стандартным методикам $[5,6]$.

Воздушно-сухие образцы (влажность 11,0 - 13,6\%) насыщали газообразным аммиаком в динамических условиях на установке, описанной в [7]. Количество поглощенного аммиака оценивали, определяя содержание общего азота в исходном и аммонизированном образцах по методу Кьельдаля [8]. Для определения прочности закрепления аммиака образцы подвергали сушке при $105{ }^{\circ} \mathrm{C}$ в течение 1 ч.

Исследуемые образцы запрессовывали в таблетки с бромистым калием. Методика регистрации и обработки спектров ЭПР приведена в [9]. Информативность метода ЭПР объясняется тем, что парамагнетизм торфа обусловлен не классическими свободными радикалами той или иной природы, стабилизированными жесткой матрицей, а выигрышем энергии при формировании надмолекулярных ассоциатов вследствие синергического эффекта взаимодействия ароматических фрагментов и водородных связей [10]. В подобных парамагнитных ассоциатах имеет место не миграция неспаренного электрона как частицы, а характерная для подобных низкоразмерных структур делокализация спиновой плотности [11], что придает неспаренному электрону функцию «молекулярного репортера».

Данные, представленные в таблицах 1 и 2, наглядно демонстрируют, что фактическая сорбция аммиака существенно (в $3-4,5$ раза) превышает ионообменную емкость и верхового и низинного торфа. Предварительная обработка торфа исследуемыми кислотами приводит к повышению поглощения аммиака еще на $6,4-39,7 \%$. При этом наблюдается корреляция усиления сорбционной активности с ростом концентрации раствора кислоты и модуля.

На первый взгляд, приведенные результаты представляются вполне тривиальными, поскольку хорошо известна технология обработки органогенных сорбентов аммиака минеральными кислотами с целью увеличения содержания в них ионообменных групп [2, 3].

Однако проведенные расчеты свидетельствуют, что концентрация внедренных функциональных групп существенно ниже эффекта усиления сорбционной активности. Рассмотрим для примера ситуацию, имеющую место при обработке торфа щавелевой кислотой. Очевидно, что предельно возможное содержание допирующих карбоксильных групп (при допущении полного внедрения молекул кислоты в органическую матрицу торфа) будет иметь место при использовании раствора $10^{-2}$ моль л$^{-1}$ с модулем $5: 1$, а предельно возможное количество внедренных в матрицу торфа молекул кислоты не превысит $5 \cdot 10^{-2}$ ммоль $\Gamma^{-1}$. Поскольку щавелевая кислота является двухосновной кислотой, увеличение обменной емкости в этом случае составит $10^{-1}$ мг-экв $\Gamma^{-1}$, тогда как по данным, представленным в таблице 1 , сорбция аммиака пушицевым торфом возрастает на 1,5 мг-экв· $\Gamma^{-1}$, т.е. в 15 раз выше. Еще большее различие имеет место при обработке пушицевого торфа слабым раствором щавелевой кислоты $\left(10^{-4}\right.$ моль $\left.л^{-1}\right)$ с меньшим модулем (2,5 : 1). При этом возрастание обменной емкости за счет внедрения молекул кислоты в органическую матрицу торфа не может превышать $5 \cdot 10^{-4}$ мг-экв $\Gamma^{-1}$. Наблюдаемое же повышение исследуемого параметра (таблица 1) составляет 1 мг-экв· $\Gamma^{-1}$, т.е. больше в 2000 раз. Для всей совокупности исследованных образцов (даже при допущении полного внедрения кислот в матрицу торфа) усиление сорбционной активности превосходит концентрацию допирующих ионообменных групп в 5-2000 раз. 
Таблица 1. Влияние кислот на сорбционные и технологические свойства сорбентов на основе пушицевого торфа

\begin{tabular}{|c|c|c|c|c|}
\hline Образец & $\begin{array}{c}\text { Насыпная плот- } \\
\text { ность, кг }{ }^{-3}\end{array}$ & $\begin{array}{c}\text { Водопоглощение, } \\
\% \\
\end{array}$ & Прочность, МПа & $\begin{array}{c}\text { Поглощение } \\
\text { аммиака, мг-экв } \cdot \Gamma^{-1}\end{array}$ \\
\hline Торф исходный & 520 & 102,0 & 11,8 & 3,7 \\
\hline $\begin{array}{l}\text { Торф, обработанный } \mathrm{H}_{3} \mathrm{PO}_{4}\left(\mathrm{C}=10^{-4} \text { моль } \cdot \pi^{-1}\right) \text {, } \\
\text { М 2,5: } 1\end{array}$ & 561 & 73,0 & 11,9 & 4,0 \\
\hline $\begin{array}{l}\text { Торф, обработанный } \mathrm{H}_{3} \mathrm{PO}_{4}\left(\mathrm{C}=10^{-4} \text { моль } \cdot \pi^{-1}\right) \text {, } \\
\text { М } 5: 1\end{array}$ & 529 & 88,8 & 12,0 & 4,1 \\
\hline $\begin{array}{l}\text { Торф, обработанный } \mathrm{H}_{3} \mathrm{PO}_{4}\left(\mathrm{C}=10^{-2} \text { моль } \cdot \pi^{-1}\right) \text {, } \\
\text { М 2,5: } 1\end{array}$ & 554 & 61,0 & 12,2 & 4,8 \\
\hline $\begin{array}{l}\text { Торф, обработанный } \mathrm{H}_{3} \mathrm{PO}_{4}\left(\mathrm{C}=10^{-2} \text { моль } \cdot{ }^{-1}\right) \text {, } \\
\text { М } 5: 1\end{array}$ & 535 & 66,0 & 12,6 & 4,9 \\
\hline $\begin{array}{l}\text { Торф, обработанный лимонной кислотой } \\
\left(\mathrm{C}=10^{-4} \text { моль }^{-1}{ }^{-1}\right), \text { M } 2,5: 1\end{array}$ & 563 & 109,8 & 14,9 & 4,1 \\
\hline $\begin{array}{l}\text { Торф, обработанный лимонной кислотой } \\
\left.\left(\mathrm{C}=10^{-4} \text { моль }^{-1}\right)^{-1}\right), \text { M } 5: 1\end{array}$ & 560 & 111,8 & 15,1 & 4,2 \\
\hline $\begin{array}{l}\text { Торф, обработанный лимонной кислотой } \\
\left.\left(\mathrm{C}=10^{-2} \text { моль }^{-1}\right)^{-1}\right), \text { M } 2,5: 1\end{array}$ & 568 & 115,6 & 15,4 & 4,4 \\
\hline $\begin{array}{l}\text { Торф, обработанный лимонной кислотой } \\
\left(\mathrm{C}=10^{-2} \text { моль }^{-1}{ }^{-1}\right), \text { M } 5: 1\end{array}$ & 562 & 110,5 & 15,2 & 4,5 \\
\hline $\begin{array}{l}\text { Торф, обработанный щавелевой кислотой } \\
\left(\mathrm{C}=10^{-4} \text { моль } \cdot \pi^{-1}\right), \text { M 2,5 : } 1\end{array}$ & 560 & 119,6 & 15,0 & 4,7 \\
\hline 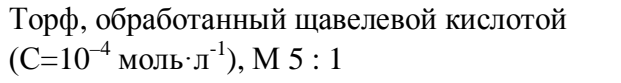 & 559 & 120,0 & 15,2 & 4,9 \\
\hline $\begin{array}{l}\text { Торф, обработанный щавелевой кислотой } \\
\left(\mathrm{C}=10^{-2} \text { моль } \cdot \pi^{-1}\right), \text { M 2,5 : } 1\end{array}$ & 568 & 123,0 & 15,9 & 5,1 \\
\hline $\begin{array}{l}\text { Торф, обработанный щавелевой кислотой } \\
\left(\mathrm{C}=10^{-2} \text { моль } \cdot{ }^{-1}\right), \text { M } 5: 1\end{array}$ & 565 & 125,4 & 15,6 & 5,2 \\
\hline
\end{tabular}

Таблица 2. Влияние кислот на сорбционные и технологические свойства сорбентов на основе осокового торфа

\begin{tabular}{|c|c|c|c|c|}
\hline Образец & $\begin{array}{c}\text { Насыпная плот- } \\
\text { ность, кг· }{ }^{-3} \\
\end{array}$ & \begin{tabular}{|c|} 
Водопоглощение, \\
$\%$
\end{tabular} & Прочность, МПа & $\begin{array}{c}\text { Поглощение } \\
\text { аммиака, мг-экв } \cdot \Gamma^{-1} \\
\end{array}$ \\
\hline Торф исходный & 580 & 110,0 & 16,5 & 2,8 \\
\hline $\begin{array}{l}\text { Торф, обработанный } \mathrm{H}_{3} \mathrm{PO}_{4}\left(\mathrm{C}=10^{-4} \text { моль } \cdot \pi^{-1}\right) \text {, } \\
\text { М } 2.5: 1\end{array}$ & 650 & 145,1 & 14,7 & 3,1 \\
\hline $\begin{array}{l}\text { Торф, обработанный } \mathrm{H}_{3} \mathrm{PO}_{4}\left(\mathrm{C}=10^{-4} \text { моль } \cdot \pi^{-1}\right) \text {, } \\
\text { М } 5: 1\end{array}$ & 630 & 129,4 & 16,5 & 3,2 \\
\hline $\begin{array}{l}\text { Торф, обработанный } \mathrm{H}_{3} \mathrm{PO}_{4}\left(\mathrm{C}=10^{-2} \text { моль } \cdot \pi^{-1}\right) \text {, } \\
\text { М } 2,5: 1\end{array}$ & 690 & 136,0 & 14,9 & 3,4 \\
\hline $\begin{array}{l}\text { Торф, обработанный } \mathrm{H}_{3} \mathrm{PO}_{4}\left(\mathrm{C}=10^{-2} \text { моль } \cdot{ }^{-1}\right) \text {, } \\
\text { М } 5: 1\end{array}$ & 660 & 123,7 & 16,4 & 3,5 \\
\hline 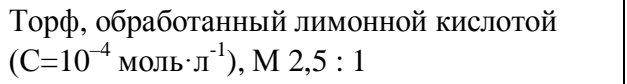 & 605 & 176,0 & 17,6 & 2,9 \\
\hline 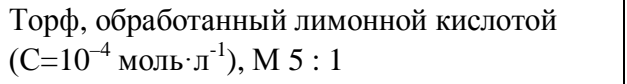 & 609 & 172,0 & 17,4 & 3,0 \\
\hline $\begin{array}{l}\text { Торф, обработанный лимонной кислотой } \\
\left(\mathrm{C}=10^{-2} \text { моль } \cdot \text { ) }\right) \text { М 2,5 : } 1\end{array}$ & 608 & 178,0 & 18,3 & 3,1 \\
\hline $\begin{array}{l}\text { Торф, обработанный лимонной кислотой } \\
\left(\mathrm{C}=10^{-2} \text { моль } \cdot{ }^{-1}\right), \text { M } 5: 1\end{array}$ & 610 & 182,0 & 18,4 & 3,2 \\
\hline $\begin{array}{l}\text { Торф, обработанный щавелевой кислотой } \\
\left(\mathrm{C}=10^{-4} \text { моль·л), M 1:2,5 }\right.\end{array}$ & 613 & 188,0 & 17,9 & 3,2 \\
\hline 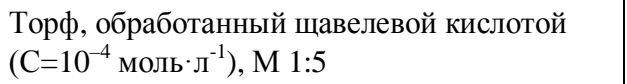 & 615 & 192,0 & 18,7 & 3,2 \\
\hline $\begin{array}{l}\text { Торф, обработанный щавелевой кислотой } \\
\left(\mathrm{C}=10^{-2} \text { моль } \cdot \pi^{-1}\right), \text { M 2,5 : } 1\end{array}$ & 618 & 194,0 & 18,0 & 3,5 \\
\hline 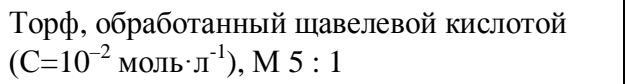 & 610 & 198,0 & 18,6 & 3,5 \\
\hline
\end{tabular}


Для установления механизмов усиления сорбционной активности исследовано влияние обработки торфа исследуемыми кислотами на спектры ЭПР рассматриваемых образцов.

Параметры спектров ЭПР исходных образцов (таблицы 3,4$)$ типичны для верхового и низинного типов торфа [9]. Низкая интенсивность сигнала ЭПР последнего обусловлена его меньшей степенью разложения. Большая ширина и меньшая степень насыщения сигнала СВЧ-мощностью (высокое значение параметра $\mathrm{A} / \mathrm{A}_{0}$ ) обусловлены значительным содержанием азота в системах полисопряжения [9].

В осоковом (низинном) торфе помимо узкого сигнала органических парамагнитных центров (ПМЦ) регистрируется и размытый спектр соединений $\mathrm{Fe}^{3+}$, что также типично для низинного торфа [9]. Сравнительно узкий сигнал в низких полях $(\Delta \mathrm{H} \sim 100 \Gamma \mathrm{c}, \mathrm{g}=4,3)$ обусловлен соединениями железа с сугубо ионной формой связи, широкий же $(\Delta \mathrm{H}=600$ - 900 Гc) c g=2,2 - соединениями железа с ковалентной формой связи, кластерами ионов. Первый обязан ионам $\mathrm{Fe}^{3+}$, связанным с карбоксильными группами органического вещества торфа. Широкий же объясняется как координационными формами связи $\mathrm{Fe}^{3+}$ с органическим веществом, так и минеральными примесями. Наличие магнитных соединений железа является дополнительным фактором, объясняющим слабое насыщение сигнала органических ПМЦ СВЧ-мощностью (высокое значение параметра $\left.\mathrm{A} / \mathrm{A}_{0}\right)$. Заметим, что в случае использованного образца пушицевого торфа также регистрируется незначительное содержание ионов $\mathrm{Fe}^{3+}$, связанных с карбоксильными группами, что, по-видимому, объясняет сравнительно слабое для случая верховых видов торфа насыщение сигнала ЭПР СВЧмощностью.

Для всех исследованных образцов сорбция аммиака приводит к согласующемуся с вышеописанными результатами существенному повышению интенсивности сигнала ЭПР и трансформации его параметров, объясняемых взаимодействием молекул аммиака с системами полисопряжения.

Обработка использованными кислотами приводит к повышению g-фактора $(\Delta \mathrm{g}$ составляет 0,0004 $\pm 0,0002$ в случае верхового торфа и 0,0003 $\pm 0,0001$ - низинного), что может быть объяснено частичной локализацией неспаренного $\pi$-электрона на атомах кислорода кислотного остатка. Для пушицевого торфа наблюдается также и усиление интенсивности сигнала ЭПР как для исходного, так и аммонизированного образцов. Последнее согласуется и с увеличением сорбционной способности. В случае осокового торфа, как видно из представленных в таблице 4 данных, наблюдается также ослабление и сужение спектра ковалентносвязанного железа, сопровождаемого усилением сигнала $\mathrm{Fe}^{3+}$ с сугубо ионной формой связи $(\mathrm{g}=4,3)$.

Таблица 3. Влияние кислот на спектры ЭПР препаратов пушицевого торфа

\begin{tabular}{|c|c|c|c|c|c|c|c|c|c|c|}
\hline \multirow{3}{*}{ Образец } & \multirow{3}{*}{$\mathrm{A}_{\mathrm{TT}}{ }^{*}$} & \multirow{2}{*}{\multicolumn{2}{|c|}{$\Delta H, \Gamma \mathrm{c}$}} & \multirow{3}{*}{$g$-фактор } & \multirow{3}{*}{$\begin{array}{l}I, 10^{17} \\
\mathrm{c} \Pi \cdot \Gamma^{-1}\end{array}$} & \multirow{3}{*}{$A / A_{0}^{* *}$} & \multicolumn{4}{|c|}{$\mathrm{Fe}^{3+}$} \\
\hline & & & & & & & \multicolumn{2}{|c|}{$g=4,3$} & \multicolumn{2}{|c|}{$g=2,2$} \\
\hline & & $0,1 \mathrm{мBт}$ & $50 \mathrm{мBт}$ & & & & $\Delta H, \Gamma \mathrm{c}$ & $\begin{array}{c}I_{\text {oтн. }}, \\
10^{6}\end{array}$ & $\Delta H, \Gamma \mathrm{c}$ & $I_{\text {отн. }}, 10^{8}$ \\
\hline Исходный торф & 46 & 4,0 & 4,0 & 2,0032 & 6,0 & 3,57 & 80 & 0,4 & & $\mathrm{He}$ \\
\hline То же после сорбции $\mathrm{NH}_{3}$ & 46,5 & 5,6 & 7,3 & 2,0039 & 10,8 & 2,99 & 80 & 0,4 & регис & трируется \\
\hline $\begin{array}{l}\text { Торф, обработанный } \mathrm{H}_{3} \mathrm{PO}_{4} \\
\left(\mathrm{C}=10^{-4} \text { моль }{ }^{-1}\right), \text { M } 2,5: 1\end{array}$ & 43,5 & 4,0 & 4,8 & 2,0039 & 6,1 & 2,74 & 80 & 0,4 & & Го же \\
\hline То же после сорбции $\mathrm{NH}_{3}$ & 42,0 & 5,8 & 7,3 & 2,0036 & 13,2 & 2,88 & 80 & 0,3 & & Го же \\
\hline $\begin{array}{l}\text { Торф, обработанный } \mathrm{H}_{3} \mathrm{PO}_{4} \\
\left(\mathrm{C}=10^{-4} \text { моль }{ }^{-1}\right), \text { M } 5: 1\end{array}$ & 43,5 & 3,7 & 4,8 & 2,0032 & 6,0 & 3,20 & 80 & 0,4 & & Го же \\
\hline То же после сорбции $\mathrm{NH}_{3}$ & 43,5 & 5,6 & 6,6 & 2,0036 & 12,9 & 3,43 & 80 & 0,3 & & Го же \\
\hline $\begin{array}{l}\text { Торф, обработанный } \mathrm{H}_{3} \mathrm{PO}_{4} \\
\left(\mathrm{C}=10^{-2} \text { моль } \cdot \pi\right), \mathrm{M} 2,5: 1\end{array}$ & 39,0 & 3,8 & 5,6 & 2,0033 & 6,2 & 2,50 & 80 & 0,3 & & Го же \\
\hline То же после сорбции $\mathrm{NH}_{3}$ & 46,5 & 5,6 & 6,6 & 2,0036 & 11,9 & 3,22 & 80 & 0,4 & & Го же \\
\hline $\begin{array}{l}\text { Торф, обработанный } \mathrm{H}_{3} \mathrm{PO}_{4} \\
\left(\mathrm{C}=10^{-2} \text { моль } \cdot{ }^{-1}\right), \text { M } 5: 1\end{array}$ & 42,0 & 4,0 & 4,8 & 2,0037 & 7,7 & 2,96 & 80 & 0,3 & & Го же \\
\hline То же после сорбции $\mathrm{NH}_{3}$ & 44,0 & 6,3 & 7,2 & 2,0036 & 17,1 & 3,34 & 80 & 0,3 & & Го же \\
\hline $\begin{array}{l}\text { Торф, обработанный лимонной ки- } \\
\text { слотой }\left(\mathrm{C}=10^{-2} \text { моль }^{-1}{ }^{-1}\right), \text { M 2,5 : } 1\end{array}$ & 43,5 & 4,0 & 4,3 & 2,0037 & 7,1 & 3,33 & 80 & 0,3 & & Го же \\
\hline То же после сорбции $\mathrm{NH}_{3}$ & 44,0 & 5,5 & 6,4 & 2,0038 & 11,2 & 2,16 & 80 & 0,3 & & Го же \\
\hline $\begin{array}{l}\text { Торф, обработанный щавелевой ки- } \\
\text { слотой }\left(\mathrm{C}=10^{-4} \text { моль }^{-1}{ }^{-1}\right), \text { M } 2,5: 1\end{array}$ & 45,0 & 3,9 & 5,0 & 2,0039 & 7,8 & 2,84 & 80 & 0,3 & & Го же \\
\hline То же после сорбции $\mathrm{NH}_{3}$ & 46,0 & 5,3 & 5,4 & 2,0033 & 15,2 & 2,81 & 80 & 0,4 & & Го же \\
\hline
\end{tabular}

Примечание: ${ }^{*} \mathrm{~A}_{\text {тт }}$ - показание аттенюатора СВЧ-тракта; ${ }^{* *} A / A_{0}-$ отношение амплитуд сигналов, снятых при 50 и 0,1 мВт. 
Таблица 4. Влияние кислот на спектры ЭПР препаратов осокового торфа

\begin{tabular}{|c|c|c|c|c|c|c|c|c|c|c|}
\hline \multirow{3}{*}{ Образец } & \multirow{3}{*}{$\mathrm{A}_{\mathrm{TT}}{ }^{*}$} & \multirow{2}{*}{\multicolumn{2}{|c|}{$\Delta H, \Gamma \mathrm{c}$}} & \multirow{3}{*}{$g$-фактор } & \multirow{3}{*}{$\begin{array}{l}I, 10^{17} \\
\mathrm{c} \Pi \cdot \Gamma^{-1}\end{array}$} & \multirow{3}{*}{$A / A_{0}^{* *}$} & \multicolumn{4}{|c|}{$\mathrm{Fe}^{3+}$} \\
\hline & & & & & & & \multicolumn{2}{|c|}{$g=4,3$} & \multicolumn{2}{|c|}{$g=2,2$} \\
\hline & & $0,1 \mathrm{мB \textrm {T }}$ & $50 \mathrm{мBт}$ & & & & $\Delta H, \Gamma \mathrm{c}$ & $\begin{array}{c}I_{\text {отн. }}, \\
10^{6}\end{array}$ & $\Delta H, \Gamma \mathrm{c}$ & $\begin{array}{c}I_{\text {отн. }}, \\
10^{8}\end{array}$ \\
\hline Исходный торф & 46,0 & 6,8 & 7,0 & 2,0035 & 3,1 & 4,87 & 80 & 0,4 & 950 & 1,15 \\
\hline То же после сорбции $\mathrm{NH}_{3}$ & 46,5 & 7,0 & 8,5 & 2,0036 & 6,1 & 5,63 & 110 & 1,9 & 900 & 1,13 \\
\hline $\begin{array}{l}\text { Торф, обработанный } \mathrm{H}_{3} \mathrm{PO}_{4} \\
\left(\mathrm{C}=10^{-4} \text { моль }{ }^{-1}\right), \text { M } 2,5: 1\end{array}$ & 42,5 & 6,6 & 7,2 & 2,0040 & 2,8 & 5,08 & 110 & 1,7 & 810 & 0,83 \\
\hline То же после сорбции $\mathrm{NH}_{3}$ & 46,5 & 7,2 & 8,5 & 2,0040 & 5,5 & 5,63 & 110 & 1,9 & 690 & 0,82 \\
\hline $\begin{array}{l}\text { Торф, обработанный } \mathrm{H}_{3} \mathrm{PO}_{4} \\
\left(\mathrm{C}=10^{-4} \text { моль } \cdot \pi^{-1}\right), \text { M } 5: 1\end{array}$ & 45,5 & 6,6 & 7,2 & 2,0037 & 2,8 & 5,32 & 110 & 2,3 & 660 & 0,73 \\
\hline То же после сорбции $\mathrm{NH}_{3}$ & 47,0 & 7,1 & 7,4 & 2,0040 & 5,6 & 5,45 & 110 & 2,6 & 710 & 0,68 \\
\hline $\begin{array}{l}\text { Торф, обработанный } \mathrm{H}_{3} \mathrm{PO}_{4} \\
\left(\mathrm{C}=10^{-2} \text { моль } \cdot \pi^{-1}\right) \mathrm{M} 2,5: 1\end{array}$ & 39,5 & 6,9 & 7,3 & 2,0038 & 3,2 & 4,37 & 110 & 2,4 & 680 & 0,70 \\
\hline То же $+\mathrm{NH}_{3}$ & 46,5 & 7,0 & 8,5 & 2,0036 & 6,1 & 5,63 & 110 & 2,4 & 660 & 0,75 \\
\hline $\begin{array}{l}\text { Торф, обработанный } \mathrm{H}_{3} \mathrm{PO}_{4} \\
\left(\mathrm{C}=10^{-2} \text { моль } \cdot^{-1}\right), \text { M } 5: 1\end{array}$ & 42,0 & 6,2 & 6,3 & 2,0038 & 2,7 & 5,83 & 110 & 1,9 & 670 & 0,75 \\
\hline То же после сорбции $\mathrm{NH}_{3}$ & 46,0 & 7,1 & 9,0 & 2,0041 & 5,5 & 6,72 & 110 & 2,1 & 690 & 0,73 \\
\hline $\begin{array}{l}\text { Торф, обработанный лимонной ки- } \\
\text { слотой }\left(\mathrm{C}=10^{-2}{\text { моль }{ }^{-1}}^{-1}\right), \mathrm{M} 2,5: 1\end{array}$ & 40,0 & 6,4 & 8,0 & 2,0039 & 5,1 & 4,59 & 110 & 2,2 & 635 & 0,68 \\
\hline То же после сорбции $\mathrm{NH}_{3}$ & 47,0 & 7,2 & 7,6 & 2,0040 & 9,4 & 5,60 & 110 & 2,7 & 640 & 0,67 \\
\hline $\begin{array}{l}\text { Торф, обработанный щавелевой ки- } \\
\text { слотой }\left(\mathrm{C}=10^{-2}{\text { моль }{ }^{-1}}^{-1}\right) \text { M } 2,5: 1\end{array}$ & 43,0 & 5,8 & 6,3 & 2,0036 & 5,7 & 4,23 & 110 & 1,6 & 700 & 0,74 \\
\hline То же после сорбции $\mathrm{NH}_{3}$ & 47,0 & 7,1 & 7,8 & 2,0038 & 6,6 & 5,62 & 110 & 1,7 & 715 & 0,95 \\
\hline
\end{tabular}

Примечание: " $\mathrm{A}_{\text {тт }}$ - показание аттенюатора СВЧ-тракта; ${ }^{* *} A / A_{0}-$ отношение амплитуд сигналов, снятых при 50 и 0,1 мВт.

При действиях с образцами торфа, обработанного кислотами, имеет место небольшое, но достоверное падение добротности измерительного резонатора, что проявляется в необходимости повышения уровня СВЧ-мощности, подаваемой в резонатор, для сохранения тока СВЧ-детектора (уменьшение параметра $\mathrm{A}_{\text {тт}}$ ). Данное падение доказывает внедрение кислот в матрицу торфа и объясняется диэлектрическими потерями, вносимыми их полярными молекулами. Падение добротности сильнее при обработке раствором кислот с концентрацией $10^{-2}$ моль л $^{-1}$. Последующая же обработка аммиаком стремится вернуть добротность резонатора к исходному состоянию, что логично объясняется реакцией нейтрализации.

Для понимания столь наглядного влияния низких концентраций слабых кислот на спектры ЭПР торфа следует принять во внимание, что использованные кислоты являются двух- (щавелевая) и трехосновными (фосфорная и лимонная). Поэтому правомерно провести аналогию с действием непарамагнитных поливалентных катионов металлов [12]. Можно предполагать, что они образуют мостиковые водородные и донорно-акцепторные связи между полисопряженными фрагментами. Поскольку при этом неспаренные $\pi$-спины частично локализованы на атомах кислорода кислотных групп, то имеет место возрастание g-фактора сигнала органических ПМЦ, а также уширение его с повышением уровня СВЧ-мощности. Предложенная аналогия обосновывается наибольшим улучшением сорбционной активности и усилением сигнала ЭПР при использовании двухосновной щавелевой кислоты, поскольку двухвалентные катионы металлов эффективнее модифицируют системы полисопряжения гуминовых кислот по сравнению с трехвалентными [12].

Однако наблюдаются и принципиальные отличия по сравнению с сорбцией гумусовыми образованиями непарамагнитных поливалентных катионов. Во-первых, влияние последних на спектры ЭПР проявляется при концентрации не ниже 1 мг-экв $\Gamma^{-1}[13]$. Влияние же кислот регистрируется уже при $\mathrm{C}=2,5 \cdot 10^{-4} \mathrm{M \Gamma -экв} \cdot \Gamma^{-1}$. К тому же для Ме-форм характерно наличие двух типов ПМЦ: 1 - в структуре которых находится ион металла и 2 - исходные ПМЦ [12]. Поэтому для них трансформация параметров сигнала ЭПР сопровождается существенным усилением его интенсивности. В нашей же ситуации оно незначительно.

Для понимания данных различий необходимо принять во внимание развитые в работе [14] представления о «микрокоординации» и «макрокоординации» при взаимодействии ионов металлов с гуминовыми кислотами (ГК). Под первой понимается процесс связывания с катионами отдельных функциональных групп с образованием координационных узлов, под «макрокоординацией» - связывание катионов клубком макромолекул с формированием макромолекулярных комплексов. 
Очевидно, что при взаимодействии сорбента с ионами металлов последовательность заполнения места сорбции осуществляется согласно принципу выигрыша энергии. В случае карбоксильных катионитов, каковым по существу является торф, энергетически выгодным является взаимодействие ионов металлов непосредственно с карбоксильными группами, т.е. сорбция по механизму «микрокоординации». Поскольку в экспериментах, описанных в $[12,13]$, концентрация ионов металлов не превышала содержания карбоксильных групп, то реализовывался только механизм «микрокоординации». Поэтому локализация неспаренного спина на ионах металла имела место только в сформированных ими координационных узлах. В связи с этим в данных работах регистрировались два сигнала ЭПР, обусловленные неспаренными спинами, как локализованными на внедренном ионе металла, так и исходными.

Естественно, что использованные кислоты по своей химической природе не могут взаимодействовать непосредственно с карбоксильными группами, т.е. внедряться в структуру органической массы торфа по механизму «микрокоординации». Для них возможно только взаимодействие с клубком макромолекул, сформированных полисопряженными фрагментами, благодаря образованию водородных и донорноакцепторных связей, т.е. сорбция кислот осуществляется по механизму «макрокоординации». В связи с этим практически все неспаренные $\pi$-электроны «чувствуют» присутствие кислотных остатков, несмотря на низкое содержание последних.

Заметим, что вследствие особенностей химических свойств аммиака, а именно, образования катионов аммония в водной среде и способности к формированию водородных и донорно-акцепторных связей, во взаимодействии его с органической матрицей торфа задействованы два механизма - «микрокоординации» и «макрокоординации».

Эффективностью механизма «макрокоординации» можно объяснить и существенное влияние низких концентраций слабых кислот на структуру органоминеральных комплексов образцов осокового торфа (таблица 4). Падение регистрируемой интенсивности сигнала ЭПР органической матрицы последнего при обработке фосфорной кислотой согласуется с усилением сигнала ионносвязанного железа $(\mathrm{g}=4,3)$. Ионы $\mathrm{Fe}^{3+}$, ответственные за данный сигнал, вследствие особенностей своей топологии относительно органических ПМЦ оказывают более сильное «тушащее» действие на их сигнал ЭПР по сравнению с соединениями железа, ответственными за более интенсивный спектр в области $\mathrm{g}=2,2$ [15].

Концепция трансформации надмолекулярных ассоциатов, формируемых системами полисопряжения, логично объясняет и влияние допирования низкими концентрациями слабых кислот на технологические параметры сорбента - повышение насыпной плотности, улучшение прочностных и водно-физических характеристик (табл. 1, 2). С нею согласуется положительное влияние концентрации раствора, как на сорбционную активность получаемого сорбента, так и его технологические характеристики. Наибольшее влияние на последние двухосновной щавелевой кислоты, в согласии с упомянутым выше усилением его сорбционной активности и сигнала ЭПР, также подтверждает предлагаемую концепцию.

В то же время обращают на себя внимание экспериментальные результаты, полученные в случае обработки торфа фосфорной кислотой. Они объясняются образованием гемигидратов [16], пригодных к использованию в качестве осушителей воздуха [17]. Избыточные молекулы воды взаимодействуют с молекулами $\mathrm{H}_{2} \mathrm{O}$ гемигидратов, образуя тем самым гидратные прослойки [18]. Высокое содержание влаги логично объясняет более низкий уровень водопоглощения по сравнению с сорбентами, полученными при обработке лимонной и щавелевой кислотами (в случае верхового торфа наблюдается даже его падение по сравнению с исходным образцом), а также высокая насыпная плотность сорбентов на основе осокового торфа. Наличие гидратных прослоек объясняет отсутствие усиления прочности и интенсивности сигнала ЭПР [13], в случае осокового торфа имеет место даже ослабление данных характеристик по сравнению с исходным образцом.

Меньшую эффективность лимонной кислоты в усилении сорбционной активности можно объяснить тем, что она является более слабой кислотой по сравнению с фосфорной и щавелевой.

Можно утверждать, что более сложный характер влияния кислот на сорбционные, спектральные и технологические характеристики сорбентов на основе осокового торфа, по сравнению с получаемыми на основе пушицевого, обусловлен трансформацией органоминеральных комплексов первых.

Результаты выполненных исследований являются научными основами получения и применения биосферносовместимых сорбентов на основе торфа для очистки газовых выбросов от токсичных загрязнений, в первую очередь, аммиака. Производственные испытания, выполненные на птицефабриках Минской 
области, показали экономическую целесообразность использования торфяных сорбентов для очистки воздушных сред, обусловленную уменьшением падежа птицы при увеличении среднесуточного привеса, а также снижением энергозатрат и выплат экологического налога, экономией производственных затрат (медикаменты, ветобслуживание и т.д.).

\section{Выводы}

Показано, что причиной усиления сорбционной активности и улучшения технологических характеристик сорбентов на основе торфа при модификации его низкими концентрациями слабых кислот является трансформация систем полисопряжения и связанная с нею перестройка структуры органоминеральных комплексов. Взаимодействие модифицирующих кислот с органической матрицей торфа происходит по механизму «макрокоординации».

Разработаны научные основы получения сорбционных материалов на основе торфа для решения проблем очистки воздушных сред от аммиака.

\section{Список литературь}

1. Плященко С.И., Хохлов И.И. Микроклимат и продуктивность животных. Л., 1987. 64 с.

2. Жуков В.К., Томсон А.Э., Самсонова А.С., Соколова Т.В., Николаенков А.И. Новые аспекты получения и применения адсорбционных материалов на основе торфа // Природопользование. 2002. Вып. 8. С. 167.

3. Патент №7747 (РБ). Способ очистки газов от аммиака / С.Е. Орехова, Н.А. Шманькова, Л.И. Хмылко, В.А. Ашуйко. 28.02.2006.

4. Цыганов А.Р., Томсон А.Э., Боголицын К.Г., Соколова Т.В., Стригуцкий В.П., Пехтерева В.С., Селянина С.Б., Парфенова Л.Н., Труфанова М.В. // Фундаментальные исследования. 2013. № 4. Ч. 2. С. 345-350

5. Лиштван И.И., Король Н.Т. Основные свойства торфа и методы их определения. Минск, 1975. 320 с.

6. Головач А.А., Куптель Г.А., Терентьев А.А. Лабораторный практикум по физике и химии торфа. Ч. 1. Физико-технические свойства торфа. Минск, 1980. 69 с.

7. Томсон А.Э., Соколова Т.В., Навоша Ю.Ю. и др. // Природопользование. 2001. Вып. 7. С. 110.

8. ГОСТ 2671585. Удобрения органические. Методы определения общего азота. М., 1987.

9. Стригуцкий В.П., Бамбалов Н.Н., Прохоров С.Г., Смирнова В.В. // Химия твердого топлива. 1996. № 6. С. 29.

10. Лиштван И.И., Стригуцкий В.П. // Коллоидная химия в решении проблем экологии: тез. докл. Междунар. конф. Минск, 1994. С. 136.

11. Erchak D.P., Efimov V.G., Stelmakh V.F. // Phys. Status Solidi. B. 1997. Vol. 203, N2. P. 529.

12. Лиогонький Б.И., Лиштван И.И., Любченко Л.С. Роль непарамагнитных ионов металлов в формировании парамагнетизма полисопряженных структур // Доклады АН СССР. 1986. Т. 288, №6. С. 1411-1416 .

13. Навоша Ю.Ю., Пармон С.В., Прохоров С.Г. Органическое вещество торфа // Тез. докл. Междунар. симпозиума. Минск, 1995. С. 17.

14. Жоробекова Ш.Ж. Макролигандные свойства гуминовых кислот. Фрунзе, 1987. 194 с.

15. Стригуцкий Л.В. Влияние центров с короткими временами релаксации на спектры ЭПР углеродных материалов: автореф. дис. ... канд. физ.-мат. наук. Минск, 1999. 21 с.

16. Химический энциклопедический словарь. М., 1983. С. 417.

17. Рабинович В.А., Хавин В.Я. Краткий химический справочник. Л., 1977.

18. Гамаюнов Н.И., Гамаюнов С.Н. Сорбция в гидрофильных материалах. Тверь, 1997. 159 с.

Поступило в редакичю 13 сентября 2013 г. После переработки 22 октября 20132. 
Tsyganov A.R. ${ }^{l}$, Tomson A.E. ${ }^{l}$, Bogolicyn K.G. ${ }^{l}$. Sokolova T.V. ${ }^{l}$, Strigutskiy V.P. ${ }^{l}$, Pekhtereva V.S. ${ }^{l}$, Selyanina S.B. ${ }^{2 *}$, Parfenova L.N. ${ }^{2}$, Trufanova M.V. ${ }^{2}$ CREATION OF SORPTION MATERIALS BASED ON PEAT

${ }^{I}$ Institute for Nature Management NAS of Belarus, street F. Skoriny, 10, Minsk, 220114 (Republic of Belarus),

e-mail: nature@ecology.basnet.by

${ }^{2}$ Institute of Environmental Problems of the North of the Ural Branch of RAS, Severnoy Dviny Emb., 23, Arkhangelsk,

163000 (Russia),e-mail: smssb@yandex.ru

The scientific fundamentals of sorption materials peat-based solutions to the problems of air purification are obtained. Modification peat with low concentrations weak acids leads to the increase sorption activity and improved technological characteristics of peat sorbents. It is a consequence of transforming polyconjugation systems with restructuring of organic-mineral complexes. The interaction of modifying acids with organic matrix of peat arises by the mechanism «makrocoordination». The feasibility of using peat sorbents for decontamination of agricultural enterprises profile of ammonia are substantiated production tests.

Keywords: peat polymer matrix, sorption, polyconjugation system, ammonia sorbtion, mechanism "makrocoordination".

\section{References}

1. Pljashhenko S.I., Hohlov I.I. Mikroklimat i produktivnost' zhivotnyh. [Microclimate and productivity of animals]. Leningrad, 1987, 64 p. (in Russ.).

2. Zhukov V.K., Tomson A.Je., Samsonova A.S., Sokolova T.V., Nikolaenkov A.I. Prirodopol'zovanie, 2002. no. 8, pp. 167. (in Russ.).

3. Patent 7747 (BY). 2006.

4. Cyganov A.R., Tomson A.Je., Bogolicyn K.G., Sokolova T.V., Striguckij V.P., Pehtereva V.S., Seljanina S.B., Parfenova L.N., Trufanova M.V. Fundamental'nye issledovanija, 2013, no. 4, Ch. 2, pp. 345-350. (in Russ.).

5. Lishtvan I.I., Korol' N.T. Osnovnye svojstva torfa i metody ih opredelenija. [The basic properties of peat and methods of their determination]. Minsk, 1975, 320 p. (in Russ.).

6. Golovach A.A., Kuptel' G.A., Terent'ev A.A. Laboratornyj praktikum po fizike i himii torfa. Ch. 1. Fizi-kotehnicheskie svojstva torfa. [Laboratory workshop on the physics and chemistry of peat. Part 1. Physical and technical properties of peat]. Minsk, 1980, 69 p. (in Russ.).

7. Tomson A.Je., Sokolova T.V., Navosha Ju.Ju. i dr. Prirodopol'zovanie, 2001, no. 7, pp. 110. (in Russ.).

8. GOST 2671585. Udobrenija organicheskie. Metody opredelenija obshhego azota. [Organic fertilizers. Methods for determination of total nitrogen]. Moscow, 1987. (in Russ.).

9. Striguckij V.P., Bambalov N.N., Prohorov S.G., Smirnova V.V. Khimiia tverdogo topliva, 1996, no. 6, p. 29. (in Russ.).

10. Lishtvan I.I., Striguckij V.P. Tezisy dokladov Mezhdunarodnoj konferencii «Kolloidnaja himija v reshenii problem jekologii». [Abstracts of the International Conference «Colloidal chemistry in solving the problems of ecology»]. Minsk, 1994, p. 136. (in Russ.).

11. Erchak D.P., Efimov V.G., Stelmakh V.F. Phys. Status Solidi. B, 1997, vol. 203, no. 2, p. 529.

12. Liogon'kij B.I., Lishtvan I.I., Ljubchenko L.S. Doklady AN SSSR, 1986, vol. 288, no. 6, pp. 1411-1416. (in Russ.).

13. Navosha Ju.Ju., Parmon S.V., Prohorov S.G. Tezisy dokladov Mezhdunarod-nogo simpoziuma 15-19 maja 1995 g. [Abstracts of the International Symposium May 15-19, 1995]. Minsk, 1995, p. 17. (in Russ.).

14. Zhorobekova Sh.Zh. Makroligandnye svojstva guminovyh kislot. [Makroligandnye properties of humic acids]. Frunze, 1987, 194 p. (in Russ.).

15. Striguckij L.V. Vlijanie centrov s korotkimi vremenami relaksacii na spektry JePR uglerodnyh materia-lov: Avtoref. diss. kand. fiz.-mat. nauk. [Influence centers with short relaxation times on the EPR spectra of carbon materials: Candidate of Physical and Mathematical Sciences diss.]. Minsk, 1999, 21 p. (in Russ.).

16. Himicheskij jenciklopedicheskij slovar'. [Encyclopedic Dictionary of Chemistry]. Moscow, 1983, p. 417. (in Russ.).

17. Rabinovich V.A., Havin V.Ja. Kratkij himicheskij spravochnik. [A brief chemical handbook]. Leningrad, 1977. (in Russ.).

18. Gamajunov N.I., Gamajunov S.N. Sorbcija v gidrofil'nyh materialah. [Sorption in hydrophilic materials]. Tver', 1997, 159 p. (in Russ.). 